\title{
THE INFLUENCE OF HUMIDITY ON ABS Plastic Measurement Results
}

\author{
Martin Melichar, Dana Kubátová, Jan Kutlwašer
}
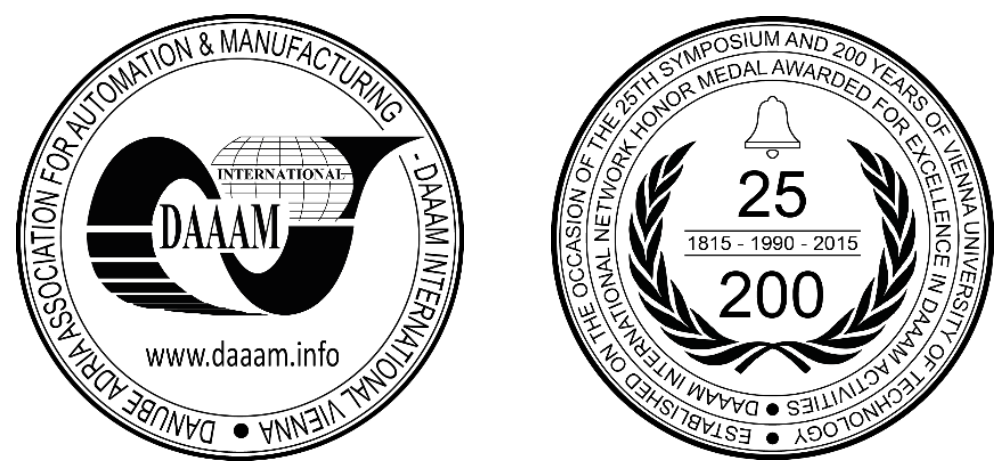

This Publication has to be referred as: Melichar, M[artin]; Kubatova, D[ana] \& Kutlwaser, J[an] (2018). The Influence of Humidity on ABS Plastic Measurement Results, Proceedings of the 29th DAAAM International Symposium, pp.0440-0444, B. Katalinic (Ed.), Published by DAAAM International, ISBN 978-3-902734-20-4, ISSN 1726-9679, Vienna, Austria

DOI: $10.2507 / 29$ th.daaam.proceedings.065

\begin{abstract}
This paper deals with effect of changing humidity in metrology lab during measuring process. Team of researchers simulated different conditions in metrology lab = stabile temperature and different humidity. During experiment CMM Carl Zeiss Prismo was used. The main question was, if there is effect of humidity $30-60 \%$ for results of measurement of basic parameters. As tested material team used ABS injection plastic which is the basic mold injection plastic material in automotive industry. The result show and describe effect and importance of stabile conditions in metrology lab and during storage of products.
\end{abstract}

Keywords: CMM; humidity; laboratory; precision of measurement, ABS plastic

\section{Introduction}

Although the current social mood of plastics and products from them is not too inclined, it is remaining fact that plastics for their unique features find enormously broad application in all areas of industrial production. In areas such as automotive production, plastics processing is among the priority fields.

The Accredited Metrology Laboratory of Regional Technology Institute, Faculty of Mechanical Engineering, West Bohemian University has been working for long period with industry partners across the whole automotive supply chain. The current IATF automotive standard clearly states that if a manufacturer (automotive) does not want to or cannot carry out some of the measurements required by the customer himself, one of the accredited laboratories within the meaning of standard 17025 must do this measurement.[1], [3]

The accredited metrology laboratory shall always have controlled environment conditions in order to achieve repeatability and reproducibility of its measurement. For the field of temperature, this requirement is quite clear, relevant and now largely implemented in laboratory systems and measurement centres. However, the humidity environment parameter remains a specific chapter. The standard for the CMM 10360-2, however, indicates the reference value of $50 \pm 10 \%$, but this is the recommended value for $3 \mathrm{D}$ measuring machines and not for the products. This paper describes an experiment in which the impact on precision of measurement outputs of the plastic parts for the automotive industry has been verified in a controlled environment change. 


\section{Experiment description}

The experiment was conducted under controlled conditions at a constant temperature of $20 \pm 2{ }^{\circ} \mathrm{C}$. During the experiment only 1 operator performed measurements to eliminate the reproducibility error. This operator repeatedly measured the selected parameters on samples of ABS plastic part. Selected parameters $=$ Inner diameter, wall thickness, length describe main metrology tasks for ABS evaluation. The measurement itself was performed on the CMM Carl Zeiss Prismo 7 Navigator equipped with a fixed sensor head with an measurement uncertainty of $0.9 \mu \mathrm{L} / 350 \mu \mathrm{m}$. [1], [5], [8] The measurements were carried out gradually at 30\%, 45\%, 60\% humidity. Total of 5 samples of the same test sample being performed at each value due to the relevance of subsequent statistical data processing.

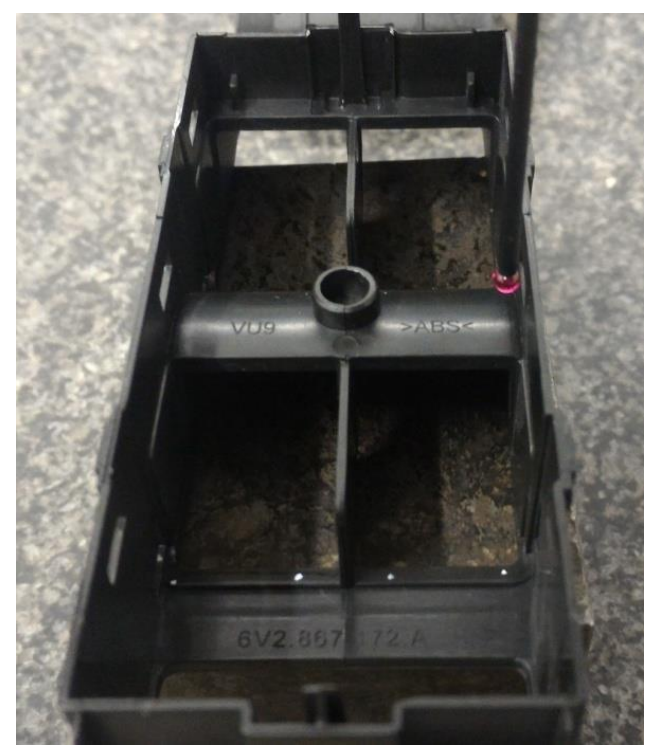

Fig. 1. Tested sample

\section{Statistical processing}

After obtaining the raw data, these data were mathematically processed in order to create a mathematical description of the influence of ambient humidity on the resulting value of the measurement for the chosen shape parameters. As it is clear from the output, the resulting measurement value changes at 30\%, 45\%,60\%. The specified mathematical formula may be a useful tool for industrial practice, especially for the situations where measurement does not take place in a controlled environment of a metrology laboratory.[4]

\subsection{Parameter length_1_Y}

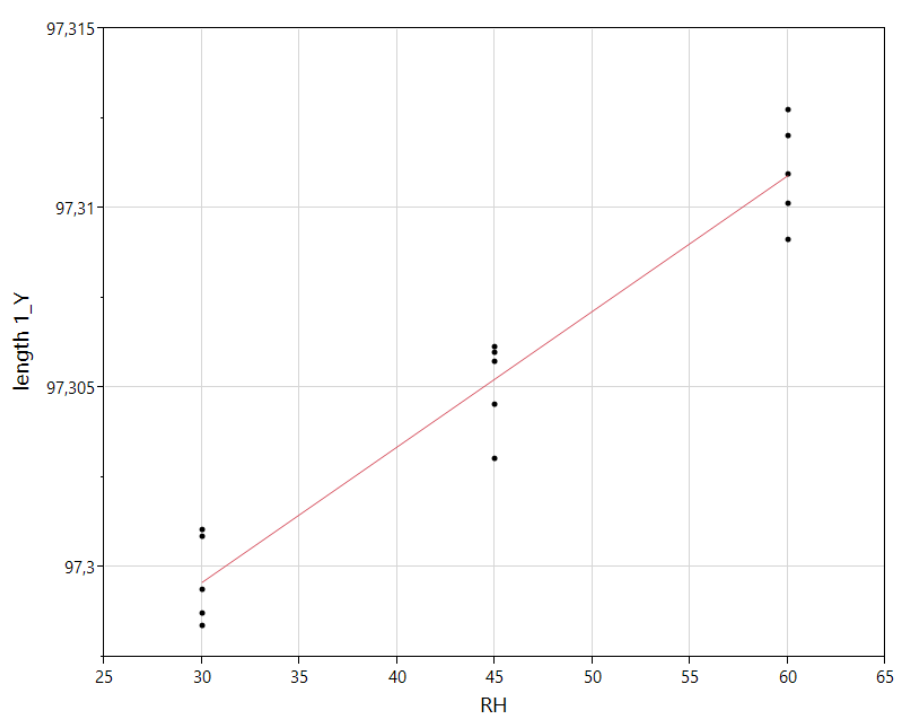

Fig. 2. Chart dependence for length_1Y 


\begin{tabular}{|c|c|}
\hline Parameter & Value \\
\hline RSquare & 0,937721 \\
\hline RSquareAdj & 0,93293 \\
\hline Root Mean Square Error & 0,001279 \\
\hline Mean of Response & 97,30526 \\
\hline Observations (or Sum Wgts) & 15 \\
\hline
\end{tabular}

Table 1. Parameters of dependence for length_1Y

The predictive model of the length dependence of the change of the humidity value RH (1) describes $93.293 \%$ of the variability of the studied variable on the basis of the adjusted index of determination (RSquareAdj). [9] Therefore, the model predicts within the moisture interval 30 to $60 \%$ with an accuracy of $93.293 \%$, with an average value of the measured quantity being 97.30526 .

\begin{tabular}{|c|c|c|c|c|c|}
\hline Source & DF & Sum of Squares & Mean Square & F Ratio & Prob $>$ F \\
\hline Model & 1 & 0,00032 & 0,00032 & 195,7368 & $<, 0001$ \\
\hline Error & 13 & $2,13 \mathrm{E}-05$ & $1,64 \mathrm{E}-06$ & & \\
\hline C. Total & 14 & 0,000342 & & & \\
\hline
\end{tabular}

Table 2. Prediction model for length_1Y

From the ANOVA analysis table, the model used is adequate based on the Fischer-Snedecor test criterion and therefore we can say that at the selected level of significance $\alpha=5 \%$, there is at least one factor (predictor) in the model that varies from zero.

\begin{tabular}{|c|c|c|c|c|}
\hline Term & Estimate & Std Error & t Ratio & Prob $>|\mathbf{t}|$ \\
\hline Intercept & 97,28827 & 0,001258 & 77338 & $<, 0001$ \\
\hline RH & 0,000377 & 0,000027 & 13,99 & $<, 0001$ \\
\hline
\end{tabular}

Table 3. Parameters of dependence formula

The table shows that the greatest effect on the change in the value of length $1 \mathrm{Y}$ is the absolute intercept. It hides all the neglected factors we have not considered in the experiment. But, at the chosen level of significance $\alpha=5 \%$, the RH moisture value is statistically significant. The model itself can therefore be expressed in the form of:

$$
\text { lenght_1_Y }=97,28827+3,77 \cdot 10^{-4} \cdot R H
$$

\subsection{Parameter wall-thickness}

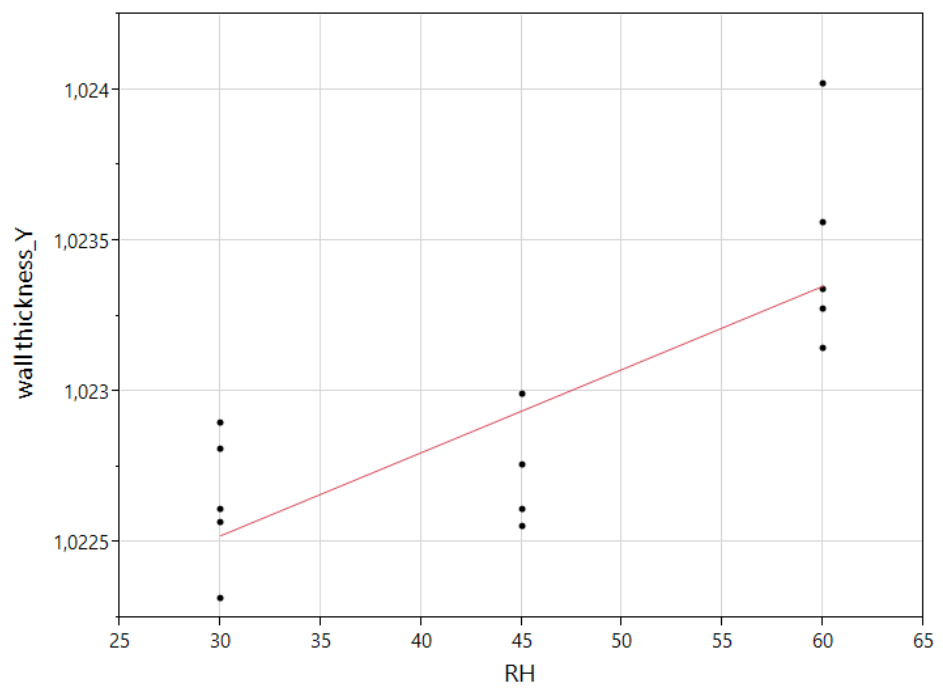

Fig. 3. Chart dependence for wall-thickness 
The essence is the same as in the first case.

\begin{tabular}{|c|c|}
\hline RSquare & $\mathbf{0 , 5 8 5 3 4 8}$ \\
\hline RSquareAdj & 0,553452 \\
\hline Root Mean Square Error & 0,000305 \\
\hline Mean of Response & 1,022937 \\
\hline Observations (or Sum Wgts) & 15 \\
\hline
\end{tabular}

Table 4. Parameters for wall-thickness

\begin{tabular}{|c|c|c|c|c|c|}
\hline Source & DF & $\begin{array}{c}\text { Sum of } \\
\text { Squares }\end{array}$ & MeanSquare & F Ratio & Prob> F \\
\hline Model & 1 & $1,71 \mathrm{E}-06$ & $1,71 \mathrm{E}-06$ & 18,3516 & 0,0009 \\
\hline Error & 13 & $1,21 \mathrm{E}-06$ & $9,32 \mathrm{E}-08$ & & \\
\hline C. Total & 14 & $2,92 \mathrm{E}-06$ & & & \\
\hline
\end{tabular}

Table 5. Prediction model for wall-thickness

\begin{tabular}{|c|c|c|c|c|c|}
\hline Term & & Estimate & StdError & t Ratio & Prob $>|\mathbf{t}|$ \\
\hline Intercept & & 1,021696 & 0,0003 & 3403 & $<, 0001$ \\
\hline RH & & $2,76 \mathrm{E}-05$ & $6,44 \mathrm{E}-06$ & 4,28 & 0,0009 \\
\hline
\end{tabular}

Table 6. Parameters of dependence formula

$$
\text { thnickness }=1,021696+2,76 \cdot 10^{-5} \cdot R H
$$

\subsection{Inner diameter}

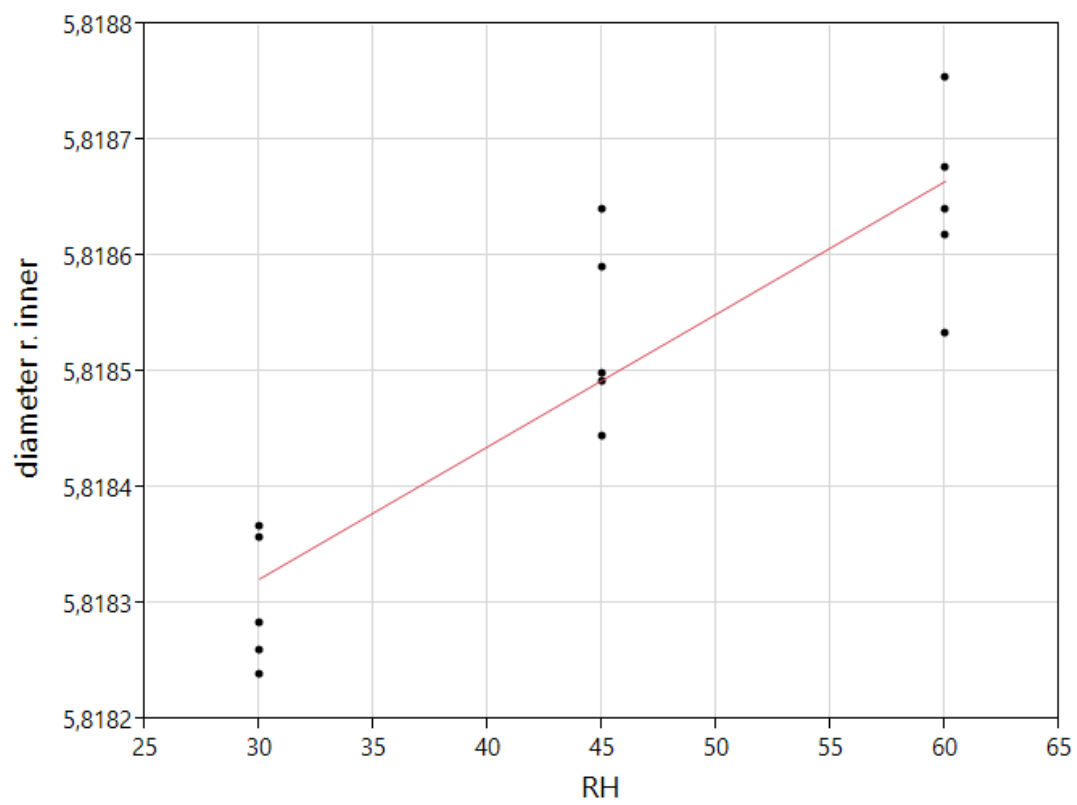

Fig. 4. Chart dependence for Inner diameter

\begin{tabular}{|c|c|}
\hline RSquare & $\mathbf{0 , 7 9 2 8 4 5}$ \\
\hline RSquareAdj & 0,77691 \\
\hline RootMeanSquareError & 0,000077 \\
\hline Mean of Response & 5,818493 \\
\hline Observations (or SumWgts) & 15 \\
\hline
\end{tabular}

Table 7. Parameters for Inner diameter 


\begin{tabular}{|c|c|c|c|c|c|}
\hline Source & DF & Sum of Squares & MeanSquare & F Ratio & Prob $>$ F \\
\hline Model & 1 & $2,94 \mathrm{E}-07$ & $2,94 \mathrm{E}-07$ & 49,755 & $<, 0001$ \\
\hline Error & 13 & $7,69 \mathrm{E}-08$ & $5,92 \mathrm{E}-09$ & & \\
\hline C. Total & 14 & $3,71 \mathrm{E}-07$ & & & \\
\hline
\end{tabular}

Table 8. Prediction model for Inner diameter

\begin{tabular}{|c|c|c|c|c|c|}
\hline Term & & Estimate & StdError & t Ratio & Prob $>|\mathbf{t}|$ \\
\hline Intercept & & 5,817978 & $7,56 \mathrm{E}-05$ & 76933 & $<, 0001$ \\
\hline RH & & $1,14 \mathrm{E}-05$ & $1,62 \mathrm{E}-06$ & 7,05 & $<, 0001$ \\
\hline
\end{tabular}

Table 9. Parameters of dependence formula

diameter $=5,817978+1,14 \cdot 10^{-5} \cdot \mathrm{RH}$

\section{Conclusion}

The article deals with one of the often overlooked influences when measuring plastic parts - environmental humidity. As part of the experiment in an accredited laboratory, the selected parameters were repeatedly measured on samples made from ABS plastic. These measurements were carried out at constant humidity levels of $30 \%, 45 \%, 60 \%$. The results obtained during experiment were mathematically processed and for the main parameters (length, thickness, inner diameter) the mathematical dependences were found. The formulas that describes the behaviour of controlled parameters when changing the humidity of the environment and may be a useful tool for industrial practice where measurement uncertainty is not determined, but the moisture parameter must be taken into account.

As the future plan of the experiment team will test behaviour of different materials, under the same conditions as described in this paper. The final goal is to create manual for metrology of the basic materials in the field of automotive and aerospace industry.

\section{Acknowledgments}

This paper was created due to the project GA ZCU v Plzni: SGS-2016-005 "Research and development for innovation in field of Manufacturing processes - Technology of metal cutting II

\section{References}

[1] ZEISS [online]. [cit. 2018-09-15].

[2] Jirouek, P.: Eligibility of measurement system in the gearboxes production of Škoda auto a.s (2012) [online]. [cit. 2017-03-08].

[3] http://www.consultantiso17025.com/Uncertainty_of_measurement_UOM_calculations_for_ISO_ 17025.html [online]. [cit. 2018-09-15].

[4] Melichar M., Kubátová D., Kutlwaše J.: (2016). CMM measuring cycle and human factor, Proceedings of the 27th DAAAM International Symposium, ISBN 978-3-902734-08-2

[5] Pernikař, J.: Assessment of the competence of control means [online]. [cit. 2016-11-25]. Available from: http://gps.fme.vutbr.cz/STAH_IN FO/31_Pernikar_VUTBR.pdf

[6] Płowucha W., Jakubiec W., Wojtyła M.: Possibilities of CMM Software to Support Proper Geometrical Product Verification, Procedia CIRP, Volume 43, 2016, Pages 303-308, ISSN 2212-8271, http://dx.doi.org/10.1016/j.procir.2016.02.124 .

[7] Barini M. E., Tosello G. Chiffre d L.: Uncertainty analysis of point-by-point sampling complex surfaces using touch probe CMMs: DOE for complex surfaces verification with CMM, Precision Engineering, Volume 34, Issue 1, January 2010, Pages 16-21, ISSN 0141-6359, http://dx.doi.org/10.1016/j.precisioneng.2009.06.009 .

[8] D. Kubátová, M. Melichar, J. Kutlwašer, Evaluation of Repeatability and reproducibility of CMM equipment, In Procedia Manufacturing, Volume 13, 2017, Pages 558-564, ISSN 2351-9789, https://doi.org/10.1016/j.promfg.2017.09.091.

[9] Melichar, M; Kubatova, D;Kutlwaser, J.: (2017). Influence of CMM Velocity on Scanning Precision, Proceedings of the 28th DAAAM International Symposium, pp.0400-0409, B. Katalinic (Ed.), Published by DAAAM International, ISBN 978-3-902734-11-2, ISSN 1726-9679, Vienna, Austria DOI: 10.2507/28th.daaam.proceedings.056 